\title{
The Effects of Flipped Learning on Learning and Motivation of Upper Secondary School Physical Education Students
}

\author{
Alberto Ferriz-Valero ${ }^{1,2,3}$, Ove Østerlie ${ }^{3,4 *}$, Alfonso Penichet-Tomas ${ }^{1,5}$ and \\ Salvador Baena-Morales ${ }^{1,2}$
}

${ }^{1}$ Department of General and Specifics Didactics, University of Alicante, Alicante, Spain, ${ }^{2}$ Research Group EDUCAPHYS, Innovation in Physical Education and Physical Activity and Sport, University of Alicante, Alicante, Spain, ${ }^{3}$ Research Group DiTePES, Digital Technology in Physical Education and Sports, NTNU-Norwegian University of Science and Technology, Trondheim, Norway, ${ }^{4}$ Department of Teacher Education, Faculty of Social and Educational Science, NTNU-Norwegian University of Science and Technology, Trondheim, Norway, ${ }^{5}$ Research Group Health-Tech, Health, Physical Activity, and Sports Technology, University of Alicante, Alicante, Spain

\section{OPEN ACCESS}

Edited by: Mohammed Saqr, University of Eastern Finland, Finland

Reviewed by: Sonsoles López-Pernas, Universidad Politécnica de Madrid, Spain

José Antonio Marín Marín, University of Granada, Spain Dimitrios Paparas,

Harper Adams University, United Kingdom

*Correspondence:

Ove Østerlie

ove.osterlie@ntnu.no

Specialty section: This article was submitted to

Digital Education,

a section of the journal

Frontiers in Education

Received: 10 December 2021 Accepted: 13 January 2022

Published: 28 January 2022

Citation:

Ferriz-Valero A, Østerlie O,

Penichet-Tomas $A$ and Baena-Morales S (2022) The Effects of

Flipped Learning on Learning and Motivation of Upper Secondary School

Physical Education Students.

Front. Educ. 7:832778.

doi: 10.3389/feduc.2022.832778
New technologies are increasingly linked to the educational world. It is necessary to develop pedagogical approaches such as flipped learning so that education and technology improve the quality of teaching to contribute to quality and sustainable education. Over the years this pedagogical approach has developed quite a bit; however, the scientific literature in physical education is still limited. The objective of the present study was to quantitatively evaluate the effects of the application of flipped learning in the acquisition of the conceptual contents of sport, in the case of the present study through volleyball. A total of 265 upper secondary school students participated in the study (126 boys: $47.9 \%$ and 137 girls: $52.1 \%$ ). The total sample set was divided into two treatment groups. The first experimental treatment group received lessons with the support of flipped learning, through the Edpuzzle platform. The second treatment group or control group received the same content as the first group through traditional methodology. The findings showed that upper secondary students benefited from flipped learning in their cognitive learning about volleyball in physical education, compared to the control group. Further, the findings showed the same results on motivation, although certain differences appeared according to sex, where boys seemed to develop autonomous motivation more than girls.

Keywords: educational innovation, active methodologies, motivation, psychosocial factors, academic performance, edpuzzle, sport learning

\section{INTRODUCTION}

One of the current problems of education is the absence of student motivation, the lack of interest, and lack of effort to acquire new knowledge and competences (Cuenca-Ruano et al., 2021). Although in physical education (PE) most students enjoy practice, a minority of students feel unmotivated (Ntoumanis, 2001), especially in secondary education (Fernandez-Rio et al., 2020). This because their personal experiences in the discipline have been negative (Van Der Horst et al., 2007), or because new technology captures students' attention, reducing motivation for physical practice in favor of 
electronic entertainment (Castro-Sánchez et al., 2017; Gimeno et al., 2015). For this reason, new pedagogical approaches have appeared to attract student attention and consequently the acquisition of new knowledge and abilities. One of these new pedagogical approaches is called flipped learning (Bergmann and Sams, 2012). The origin of the FL approach dates to 2004, when Professors Jon Bergmann and Aaron Sams, Woodland Park High School chemistry teachers began to design their classes in a digital format, using explanatory videos as reinforcement activities for students who needed them. They realized that in addition to contributing effectively to the learning of these students, they had more time to respond to the educational needs of each student (Bergmann and Sams, 2012). From this educational approach, a double objective could be achieved: 1) to attract students' attention by using new technologies that they live with daily, and to take advantage of the greatest active practice time in the PE class (Campos-Gutiérrez et al., 2021). For this valuable reason, professionals are interested in contrasting the results applied with this approach in PE, increasing their students' physical activity time in classes. Further, teachers seek to free up more time for practice to combat the problem of sedentarism and to acquire new content and skills that are specific to PE. Considering that most students do not perform physical activity during the week except in PE classes, replacing time spent on transmitting some conceptual content by physical activity sounds very interesting from the educational and child health point of view (García et al., 2015). FL is presented as an active approach compared to more traditional teaching methods, transforming the conventional form linked exclusively to the classroom into an effective way of transmitting content. In fact, Ojalvo and Doyne (2011), described FL as a pedagogical model that aims to correct the traditional teaching model. Traditionally, for example, the content given by all subjects is provided on paper, whether as books or notes. With this new model, you can change the paper to digital support. If this material is in video format, it is preferred by the student (Østerlie and Kjelaas, 2019). It is necessary to emphasize that the FL approach does not subscribe to the idea of replacing teachers with videos, but rather that students commit themselves to their own learning in a combined process with the teacher (Jong, 2017). In fact, this approach calls for digital competence from teachers to implement it properly, as well as institutional support (Moreno-Guerrero et al., 2021).

Many studies have already investigated the effects related to students experiencing an application of the FL approach in various educational areas and levels (Akçayır and Akçayır, 2018; Birgili et al., 2021; Brewer and Movahedazarhouligh, 2018; Chen, 2016; Cheng et al., 2018; Cheng et al., 2020; Galindo Domínguez and Bezanilla, 2019; Han and Røkenes, 2020; Karabulut-Ilgu et al., 2018; Låg and Sæle, 2019; Li et al., 2021; Zou et al., 2020). However, few scholars have focused their research on potential benefits in the subject of PE. Nevertheless, there are some studies this study can relate to. In primary education, for students (aged 6-12 years), some research carried out argues that the use of this pedagogical approach allows for the improvement of specific skills in sports, for example in handball (Felgueras and Delgado 2021), or in alternative sports like Korfball (Marqués-Molías et al., 2019). Other scholars have claimed that FL in PE benefits students in achieving greater knowledge and motivation and, consequently, greater academic performance (Hinojo et al., 2020). Some results are performed in primary stage (Gómez-García et al., 2020; Hinojo et al., 2020), or in secondary school students (Østerlie and Kjelaas, 2019; Østerlie and Mehus, 2020). However, Campos-Gutiérrez et al. (2021) and Gómez-García et al. (2019) did not observe differences in motivation, but only in physical activity time. Botella et al. (2021) stated that, after applying FL in PE, intrinsic motivation understood as an activity giving satisfaction per se (described in detail in the cognitive evaluation theory or CET; Ryan and Deci, 2017) increased significantly, and that amotivation (the total lack of motivation) values decreased in the FL group. These same authors claimed that FL allowed using more time for activity in PE classes, and, consequently, $\mathrm{PE}$ was perceived as more fun for the students. Further, Botella et al. (2021) and Koh et al. (2020) argues that the use of FL promotes self-learning and improves autonomy, understood as basic psychological needs (BPNT). This motivational view lies within the macro-theory of selfdetermination (SDT; Ryan and Deci, 2017). Formally, SDT comprises five mini-theories, each of which was developed to explain a set of motivationally based phenomena (Ryan and Deci, 2017). Each addresses one facet of motivation or personality functioning. One of these mini-theories, BPNT, explains the idea of developed psychological needs and their associations with psychological health and well-being. BPNT claims that psychological well-being and optimal functioning are based on autonomy, competence, and relatedness. Therefore, environments that thwart these needs invariantly impact wellness. The theory argues that all three needs are essential, and that if any is thwarted there will be distinct functional costs (Vansteenkiste et al., 2010).

After this presentation of the current literature on FL in PE in the pre-university stages, the scarce and controversial literature in this area is foregrounded. This applies especially to the upper secondary school level. In addition, earlier studies have very discreet samples and varied designs. For example, some studies evaluate motivation from a qualitative perspective (Østerlie and Kjelaas, 2019), or with different approaches to motivation to those of SDT (Hinojo et al., 2020). In this theoretical light, and considering the research earlier presented, the following hypotheses were formulated:

Hypothesis (H1). The group of students experiencing FL would increase their learning compared to the control group.

Hypothesis (H2). The group of students experiencing FL would increase their intrinsic motivation compared to the control group.

Hypothesis (H3). The group of students experiencing FL would not change their most extrinsic motivation compared to the control group.

Hypothesis (H4). The group of students experiencing FL would decrease their amotivation compared to the control group.

Overall, the purpose of this study was to quantitively evaluate the effects of the application of FL in upper secondary school students regarding the acquisition of the conceptual content of one sport, in this case volleyball. Further, this study wanted to 
TABLE 1 | Descriptive data of the sample (n) regarding sex, grade and treatment.

\begin{tabular}{|c|c|c|c|c|}
\hline Grade & Sex & Flipped group (n) & Control group (n) & Excluded (n) \\
\hline \multirow[t]{2}{*}{ Third year lower secondary school (14-15 years/o) } & Male & 30 & 39 & 9 \\
\hline & Female & 51 & 23 & 8 \\
\hline \multirow[t]{2}{*}{ Fourth year lower secondary school (15-16 years/o) } & Male & 24 & 17 & 7 \\
\hline & Female & 24 & 31 & 11 \\
\hline \multirow[t]{3}{*}{ First year upper secondary school (16-17 years/o) } & Male & 6 & 10 & 14 \\
\hline & Female & 5 & 3 & 16 \\
\hline & Total & 140 & 123 & 65 \\
\hline
\end{tabular}

$y / 0=$ years old

evaluate how this intervention affected the motivational variables understood within the SDT perspective.

\section{MATERIALS AND METHODS}

The research was carried out within the context of PE in upper secondary school. Data were collected between October and December during two academic courses (2018-19 and 2019-20) in two educational public centers in Alicante city, Spain. The present investigation is based on a natural experiment with a non-randomized controlled design with a pre- and a post-measure (Verjans-Janssen et al., 2018). The design reflected the layouts in similar studies (Botella et al., 2021; Campos-Gutiérrez et al., 2021; Cuenca-Ruano et al., 2021; Østerlie and Mehus, 2020). The study was approved by the University of Alicante's Research Ethics Committee on 2 September 2020, and given the code UA-2020-09-02.

\subsection{Sample}

The sample included third and fourth grade students of lower ( $\approx 13-14$ years old, years completed before 31st December of that same year of the intervention) and upper secondary ( $\approx 15$ years old) school who did not repeat these academic courses, and who attended PE without any limitation. Initially, 328 students participated (Table 1). After applying the exclusion criteria, a final sample of 263 students remained (126 boys: $47.9 \%$ and 137 girls: $52.1 \%$ ). Sampling was carried out by non-probabilistic conglomerates, respecting the group configurated by the two educational centers, following the criteria of compensation per ratio and sex.

Exclusion criteria were: 1) not reaching $80 \%$ attendance at the intervention lessons; 2) not completing the questionnaires pre- or post; 3) not watching the videos in Edpuzzle and belonging to the experimental group; and 4) being a member of a volleyball team in extracurricular activities. Regarding the third exclusion criterion, the educational center made the computer classroom available from 14:00 to 15:00 for students who did not have electronic devices with internet connection. All the participants were informed about the study and the educational center approved their participation and agreed to the publishing of the results anonymously. The research complied with the ethical values required in research conducted in human beings: informed consent, right to information, personal data protection, confidentiality, non-discrimination, gratuity, and the option to leave the study at any time.

\subsection{Instruments \\ 2.2.1 Motivation}

Questionnaire on Motivation in Physical Education Classes (Sánchez-Oliva et al., 2012). This questionnaire included 20 items tapping into five factors (four questions per item): intrinsic motivation (e.g., because physical education is fun), identified regulation (e.g., because I can learn skills that I could use in other areas of my life), introjected regulation (e.g., ...because it is what I have to do to feel good), external regulation (e.g., ...because it is seen by the teacher and classmates) and amotivation (e.g., ... but I don't understand why we should have physical education). These items had a closed response option, following a Likert scale from 1 to 5 , with 1 (= totally disagree) to 5 (= totally agree). After confirmatory factor analysis to check validity, an excellent fit of the data was obtained (CFI $=0.96$; $\mathrm{TLI}=0.95$; GFI $=0.95$; $\mathrm{SRMR}=0.04$ and $\mathrm{RMSEA}=0.05)$. The scale showed adequate internal consistency $(\alpha>0.70)$, as well as good nomological validity.

\subsubsection{Knowledge Test}

The volleyball knowledge test (VKT) consisted of 20 questions. The questions were created with four possible answers, with only one being valid, as agreed by the Department of Physical Education and elaborated in this research. These questions included content about technical aspects: overhead pass, forearm pass, standing serve, spike, and block. The dependent variable was calculated through the following Eq. 1:

$$
\boldsymbol{V K T}=\frac{\text { Right questions }}{2}
$$

\subsection{Procedure}

The total sample set was divided into two treatment groups. The first experimental treatment group (FLIP) received PE lessons with the support of FL. The second treatment group, or control group, (CON) received the same content as the first group (FLIP) through traditional methodology (Table 2). This traditional methodology is the methodology normally used by the physical education teacher in the rest of the lessons. In short, the first group watched videos on the Edpuzzle platform before the lessons, and the second group had notes with the same 
TABLE 2 | Research design outline.

\begin{tabular}{llcc}
\hline \multicolumn{1}{c}{ Content } & Time (min) & Group \\
\hline 1 & Motivation questionnaire (pre) & $10^{\prime}$ & Both (Only FLIP) \\
& VKT (pre) & $10-15^{\prime}$ & $20^{\prime}$ \\
& Project explanation & $10^{\prime}$ & Both \\
2 & Edpuzzle explanation & $50^{\prime}$ & Both \\
3 & Overhead pass & $50^{\prime}$ & Both \\
4 & Forearm pass & $50^{\prime}$ & Both \\
5 & Standing serve (tennis) & $50^{\prime}$ & Both \\
7 & Spike & $50^{\prime}$ & Both \\
8 & Block & $50^{\prime}$ & Both
\end{tabular}

$V K T=$ Volleyball knowledge test

content of the videos: technical aspects like overhead pass, forearm pass, standing serve, spike, and block.

On the first day of the PE class, all students were asked to complete the motivation questionnaire. After completing it, all the students completed the VKT to evaluate their prior knowledge about volleyball before the intervention was carried out. The students did not receive feedback on the results of the pre-test. To conclude this lesson, the FLIP group had explained to them the use and development of the digital platform Edpuzzle, and the control group received instructions on accessing the notes throughout the development of the work teaching unit.

In the rest of the practical lessons (lesson 2 to lesson 7), for students who received the classes with the support of FL, a digital platform with free access to video display was used, namely Edpuzzle (https://edpuzzle.com/home), where five short videos (of approx. 3-4 min) were launched for students. The first of these were dedicated to technical aspects of the overhead pass. The second was dedicated to the forearm pass, the third to standing serve, and fourth and fifth dealt with the spike and block and their execution. These videos were available on the Edpuzzle platform for students belonging to the FLIP experimental group. In addition, during the display of these videos there were quiz questions about the content, and this functioned as part of evaluation and monitoring. These videos were available up to the time of the next class in which the contents concerned were worked through. Regarding the group control using traditional methodology, the teacher provided notes with the same content treated in the videos, so that the students had access to the same information as the experimental group before the class, on the educational center platform.

Both groups received two lessons per week during the duration of the didactic unit, in total 8 lesson as described in Table 2. The last lesson was dedicated to completing the motivation questionnaire and the final VKT (post-test).

\subsection{Data Analysis}

According to Faul et al. (2007), the statistical power of the sample size was calculated using the free software $G^{\star}$ Power (Ver. 3.1.9.6, University of Dusseldorf, Germany). The sample size, 140 participants in the FLIP group and 123 participants in the CON group, with an estimated medium effect size (0.5), and a significance of $95 \%$, resulted in a power of 0.95 . All continuous variables in the data set were subjected to a normality test (Kolmogorov-Smirnov). Each variable's descriptive statistics (mean and standard deviation) were calculated. The data set was non-parametric, so the data were further subjected to a chisquare analysis and univariate statistical analysis for nonparametric samples, specifically the Mann-Whitney $U$ test, to assess the differences between the treatment groups (FLIP vs $\mathrm{CON}$ ) on two occasions: pre- and post-intervention. The Wilcoxon test was applied to observe the intra-group differences (pre vs post). To test the research hypotheses, the two study groups were compared using factorial ANOVAs 2 (time; pre-treatment vs post-treatment) x 2 (treatment; traditional intervention vs flipped learning intervention) (Quintas et al., 2020). The level of significance was established at $p<.05$ in all cases. In these non-parametric tests, the effect size (ES) was also calculated using Microsoft Excel (Version 2016) (Dominguez-Lara, 2018). This magnitude was regarded as small when values ranged between 0.1 and 0.3 , medium between 0.3 and 0.5, and large if greater than 0.5 (Cohen, 1988; Coolican, 2018). The statistical programs IBM SPSS (Version 24) and Service Solutions (International Business Machines Corp., Madrid, Spain) and Microsoft Excel in its 2016 version were used. ES was calculated by the partial eta-squared $\left(\eta_{\mathrm{p}}^{2}\right)$ in ANOVA $2 \times 2$.

\section{RESULTS}

\subsection{Baseline Differences}

The values represented by the motivational variables assessed were calculated from the average of the items of the questionnaire (e.g., intrinsic motivation value $=$ item $1+$ item $6+$ item $11+$ item 16), where the minimal result could be 1 and the maximal result 5 in each of the variables measured. A Mann-Whitney U Test (Table 3) revealed significant differences between groups at the baseline in the following variables but only in females: intrinsic motivation $(Z=-2.625, p=.009)$ and introjected regulation $(Z=$ 2.056, $p=.040)$. The ES is considered small and medium, respectively. As factorial ANOVAs $2 \times 2$ (Time $\mathrm{x}$ Treatment) was applied, the initial differences in these variables were 
TABLE 3 | Comparing variables between FLIP and CON at pre-test using Mann-Whitney $U$ test according to sex (Av \pm SD).

\begin{tabular}{|c|c|c|c|c|c|}
\hline Sex & Variables & FLIP Group & CON Group & Mann-whitney U Test & Effect size \\
\hline Male & VKT & $5.33 \pm 1.83$ & $5.36 \pm 1.83$ & 0.103 & - \\
\hline \multirow[t]{2}{*}{$\mathrm{n}_{\text {flip }}=60$} & Intrinsic M & $3.70 \pm 0.84$ & $3.90 \pm 0.77$ & 1.335 & - \\
\hline & Identified R & $3.24 \pm 0.85$ & $3.43 \pm 0.84$ & 0.934 & - \\
\hline \multirow[t]{3}{*}{$\mathrm{n}_{\mathrm{con}}=66$} & Introjected R & $1.50 \pm 0.70$ & $1.59 \pm 0.88$ & 0.052 & - \\
\hline & External R & $3.95 \pm 0.66$ & $3.77 \pm 0.74$ & -1.591 & - \\
\hline & Amotivation & $2.62 \pm 1.00$ & $2.82 \pm 1.05$ & 0.836 & - \\
\hline Female & VKT & $5.21 \pm 1.86$ & $5.23 \pm 2.00$ & 0.234 & - \\
\hline \multirow[t]{2}{*}{$\mathrm{n}_{\text {flip }}=80$} & Intrinsic M & $3.86 \pm 0.87$ & $3.46 \pm 0.94$ & $-2.625^{\star \star}$ & 0.22 \\
\hline & Identified R & $3.33 \pm 0.90$ & $3.10 \pm 0.84$ & -1.346 & - \\
\hline \multirow[t]{3}{*}{$\mathrm{n}_{\mathrm{con}}=57$} & Introjected R & $1.37 \pm 0.59$ & $1.80 \pm 0.77$ & $3.761^{\star \star \star}$ & 0.32 \\
\hline & External R & $3.69 \pm 0.85$ & $3.39 \pm 0.87$ & -1.927 & - \\
\hline & Amotivation & $2.59 \pm 0.94$ & $2.78 \pm 1.05$ & 1.210 & - \\
\hline Total & VKT & $5.26 \pm 1.84$ & $5.30 \pm 1.84$ & 0.176 & - \\
\hline \multirow[t]{2}{*}{$N_{\text {flip }}=140$} & Intrinsic M & $3.79 \pm 0.86$ & $3.70 \pm 0.88$ & -0.927 & - \\
\hline & Identified R & $3.29 \pm 0.87$ & $3.28 \pm 0.85$ & -0.189 & - \\
\hline \multirow[t]{3}{*}{$N_{\text {con }}=123$} & Introjected R & $1.43 \pm 0.64$ & $1.69 \pm 0.83$ & $2.525^{\star}$ & 0.16 \\
\hline & External R & $3.80 \pm 0.78$ & $3.60 \pm 0.82$ & $-2.193^{\star}$ & 0.14 \\
\hline & Amotivation & $2.60 \pm 0.96$ & $2.80 \pm 1.05$ & 1.414 & - \\
\hline
\end{tabular}

$V K T=$ Volleyball knowledge test; ${ }^{*} p<.05 ;{ }^{* *} p<.01 ;{ }^{* *} p<0.001$.

TABLE 4 | Comparing variables between FLIP and CON at post-test using Mann-Whitney $U$ test according to sex (Av \pm SD).

\begin{tabular}{|c|c|c|c|c|c|}
\hline Sex & Variables & FLIP Group & CON Group & Mann-whitney U Test & Effect size \\
\hline Male & VKT & $8.05 \pm 1.36$ & $6.96 \pm 1.35$ & $-4.560^{\star \star \star}$ & 0.40 \\
\hline \multirow[t]{2}{*}{$\mathrm{n}_{\text {flip }}=60$} & Intrinsic M & $4.13 \pm 0.67$ & $3.79 \pm 0.76$ & $-2.594^{\star \star}$ & 0.23 \\
\hline & Identified R & $2.98 \pm 0.88$ & $3.03 \pm 0.90$ & 0.159 & - \\
\hline \multirow[t]{3}{*}{$\mathrm{n}_{\mathrm{con}}=66$} & Introjected R & $4.32 \pm 0.61$ & $4.15 \pm 0.64$ & -1.669 & - \\
\hline & External R & $3.11 \pm 0.95$ & $3.17 \pm 0.93$ & 0.213 & - \\
\hline & Amotivation & $1.31 \pm 0.49$ & $1.48 \pm 0.70$ & 1.193 & - \\
\hline Female & $\mathrm{VKT}$ & $7.28 \pm 1.89$ & $5.79 \pm 1.61$ & $-4.883^{\star \star \star}$ & 0.42 \\
\hline \multirow[t]{2}{*}{$\mathrm{n}_{\text {flip }}=80$} & Intrinsic M & $3.87 \pm 0.87$ & $3.46 \pm 0.82$ & $-3.122^{\star \star}$ & 0.27 \\
\hline & Identified R & $2.71 \pm 0.91$ & $2.82 \pm 0.93$ & 0.579 & - \\
\hline \multirow[t]{3}{*}{$\mathrm{n}_{\mathrm{con}}=57$} & Introjected R & $3.96 \pm 0.80$ & $3.73 \pm 0.90$ & -1.579 & - \\
\hline & External R & $3.15 \pm 0.95$ & $3.02 \pm 0.89$ & -0.741 & - \\
\hline & Amotivation & $1.43 \pm 0.71$ & $1.67 \pm 0.87$ & 1.864 & - \\
\hline Total & VKT & $7.61 \pm 1.72$ & $6.42 \pm 1.58$ & $-6.049^{\star \star \star}$ & 0.37 \\
\hline \multirow{2}{*}{$\mathrm{N}_{\text {flip }}=140$} & Intrinsic M & $3.98 \pm 0.80$ & $3.64 \pm 0.80$ & $-3.779^{\star \star \star}$ & 0.23 \\
\hline & Identified R & $2.83 \pm 0.91$ & $2.93 \pm 0.92$ & 0.779 & - \\
\hline \multirow[t]{3}{*}{$\mathrm{N}_{\mathrm{con}}=123$} & Introjected R & $4.12 \pm 0.75$ & $3.95 \pm 0.80$ & -1.840 & - \\
\hline & External R & $3.13 \pm 0.95$ & $3.10 \pm 0.91$ & -0.346 & - \\
\hline & Amotivation & $1.38 \pm 0.63$ & $1.57 \pm 0.79$ & $2.001^{\star}$ & 0.12 \\
\hline
\end{tabular}

$V K T=$ Volleyball knowledge test; ${ }^{*} \mathrm{p}<.05 ;{ }^{* *} \mathrm{p}<.01 ;{ }^{* * *} \mathrm{p}<.001$.

considered. A chi-square analysis found no differences in the distribution by $\operatorname{sex}(p=.080)$.

\subsection{Comparison Between Groups Post-intervention}

The two treatment groups showed differences at the post-test in the VKT and intrinsic motivation in both males and females (Table 4). Firstly, after the intervention, the experimental group obtained higher performance in the VKT variable than the control group in both boys and girls. In addition, the Mann-Whitney $\mathrm{U}$ Test also revealed a significant difference in intrinsic motivation, being greater in the FLIP group in both male and females. In VKT, ES is considered medium, while for intrinsic motivation it is considered small.

\subsection{Comparison of Intra-groups (Pre vs Post)}

The FLIP group showed significant differences in all variables except intrinsic motivation in females (Table 5). All post-test values for pre-test increased except for identified regulation, external regulation and amotivation, which decreased. Most 
TABLE 5 | Comparing variables intra-group (pre vs post) using Wilcoxon test according to sex in flip group (Av \pm SD).

\begin{tabular}{|c|c|c|c|c|c|}
\hline Sex & Variables & PRE-test & POST-test & Wilcoxon Test & Effect size \\
\hline Male & VKT & $5.33 \pm 1.83$ & $8.05 \pm 1.36$ & $6.566^{\star \star \star}$ & 0.85 \\
\hline \multirow[t]{5}{*}{$n=60$} & Intrinsic M & $3.70 \pm 0.84$ & $4.13 \pm 0.67$ & $3.866^{\star \star \star}$ & 0.50 \\
\hline & Identified R & $3.24 \pm 0.85$ & $2.98 \pm 0.88$ & $-2.670^{\star \star}$ & 0.34 \\
\hline & Introjected R & $1.50 \pm 0.70$ & $4.32 \pm 0.61$ & $6.625^{\star \star \star}$ & 0.86 \\
\hline & External R & $3.95 \pm 0.66$ & $3.11 \pm 0.95$ & $-5.386^{\star \star \star}$ & 0.70 \\
\hline & Amotivation & $2.62 \pm 1.00$ & $1.31 \pm 0.49$ & $-5.795^{\star \star \star}$ & 0.75 \\
\hline Female & VKT & $5.21 \pm 1.86$ & $7.28 \pm 1.89$ & $6.643^{\star \star \star}$ & 0.74 \\
\hline \multirow[t]{5}{*}{$n=80$} & Intrinsic M & $3.86 \pm 0.87$ & $3.87 \pm 0.87$ & 0.142 & - \\
\hline & Identified R & $3.33 \pm 0.90$ & $2.71 \pm 0.91$ & $-5.847^{\star \star \star}$ & 0.65 \\
\hline & Introjected R & $1.37 \pm 0.59$ & $3.96 \pm 0.80$ & $7.639^{\star \star \star}$ & 0.85 \\
\hline & External R & $3.69 \pm 0.85$ & $3.15 \pm 0.95$ & $-4.432^{\star \star \star}$ & 0.50 \\
\hline & Amotivation & $2.59 \pm 0.94$ & $1.43 \pm 0.71$ & $-6.477^{\star \star \star}$ & 0.72 \\
\hline Total & VKT & $5.26 \pm 1.84$ & $7.61 \pm 1.72$ & $9.399^{\star \star \star}$ & 0.79 \\
\hline \multirow[t]{5}{*}{$N=140$} & Intrinsic M & $3.79 \pm 0.86$ & $3.98 \pm 0.80$ & $2.866^{\star \star}$ & 0.24 \\
\hline & Identified R & $3.29 \pm 0.87$ & $2.83 \pm 0.91$ & $-6.332^{\star \star \star}$ & 0.54 \\
\hline & Introjected R & $1.43 \pm 0.64$ & $4.12 \pm 0.75$ & $10.113^{\star \star \star}$ & 0.85 \\
\hline & External R & $3.80 \pm 0.78$ & $3.13 \pm 0.95$ & $-6.910^{\star \star \star}$ & 0.58 \\
\hline & Amotivation & $2.60 \pm 0.96$ & $1.38 \pm 0.63$ & $-8.689^{\star \star \star}$ & 0.73 \\
\hline
\end{tabular}

$V K T=$ Volleyball knowledge test; ${ }^{*} \mathrm{p}<.05 ;{ }^{* *} \mathrm{p}<.01 ;{ }^{* *} \mathrm{p}<.001$.

TABLE 6 | Comparing variables intra-group (pre vs post) using Wilcoxon test according to sex in control group (Av \pm SD).

\begin{tabular}{|c|c|c|c|c|c|}
\hline Sex & Variables & PRE-test & POST-test & Wilcoxon Test & Effect size \\
\hline Male & $\mathrm{VKT}$ & $5.36 \pm 1.59$ & $6.96 \pm 1.35$ & $6.492^{\star \star \star}$ & 0.80 \\
\hline \multirow[t]{5}{*}{$n=66$} & Intrinsic M & $3.90 \pm 0.77$ & $3.79 \pm 0.76$ & -1.425 & - \\
\hline & Identified R & $3.43 \pm 0.84$ & $3.03 \pm 0.90$ & $-3.443^{\star \star}$ & 0.42 \\
\hline & Introjected R & $1.59 \pm 0.88$ & $4.15 \pm 0.64$ & $6.873^{\star \star \star}$ & 0.84 \\
\hline & External R & $3.77 \pm 0.74$ & $3.17 \pm 0.93$ & $-4.936^{\star \star \star}$ & 0.60 \\
\hline & Amotivation & $2.82 \pm 1.05$ & $1.48 \pm 0.70$ & $-6.209^{\star \star \star}$ & 0.76 \\
\hline Female & VKT & $5.23 \pm 2.00$ & $5.79 \pm 1.61$ & $3.394^{\star \star}$ & 0.45 \\
\hline \multirow[t]{5}{*}{$n=57$} & Intrinsic M & $3.46 \pm 0.94$ & $3.46 \pm 0.82$ & -0.305 & - \\
\hline & Identified R & $3.10 \pm 0.84$ & $2.82 \pm 0.93$ & $-2.113^{\star}$ & 0.27 \\
\hline & Introjected R & $1.80 \pm 0.77$ & $3.73 \pm 0.90$ & $5.932^{\star \star \star}$ & 0.79 \\
\hline & External R & $3.39 \pm 0.87$ & $3.02 \pm 0.89$ & $-3.548^{\star \star \star}$ & 0.46 \\
\hline & Amotivation & $2.78 \pm 1.05$ & $1.67 \pm 0.87$ & $-4.726^{\star \star \star}$ & 0.62 \\
\hline Total & VKT & $5.30 \pm 1.79$ & $6.42 \pm 1.58$ & $7.326^{\star \star \star}$ & 0.66 \\
\hline \multirow[t]{5}{*}{$N=123$} & Intrinsic M & $3.70 \pm 0.88$ & $3.64 \pm 0.80$ & $-1.222^{\star \star \star}$ & 0.11 \\
\hline & Identified R & $3.28 \pm 0.85$ & $2.93 \pm 0.92$ & $-3.947^{\star \star \star}$ & 0.35 \\
\hline & Introjected R & $1.69 \pm 0.83$ & $3.95 \pm 0.80$ & $9.166^{\star \star \star}$ & 0.83 \\
\hline & External R & $3.60 \pm 0.82$ & $3.10 \pm 0.91$ & $-6.065^{\star \star \star}$ & 0.54 \\
\hline & Amotivation & $2.80 \pm 1.05$ & $1.57 \pm 0.79$ & $-7.756^{\star \star \star}$ & 0.69 \\
\hline
\end{tabular}

$V K T=$ Volleyball knowledge test; ${ }^{*} \mathrm{p}<.05 ;{ }^{* *} \mathrm{p}<.01 ;{ }^{* * *} \mathrm{p}<.001$.

of the ES is considered large, except for identified regulation in males, where it is small.

The control group also showed significant differences in all variables except for intrinsic motivation in both males and females (Table 6). All post-test values for pre-test decreased except for VKT and introjected regulation that increased. Intrinsic motivation remained the same in girls. The ES was considered large, except for identified regulation (medium in males and small in females) and VKT and external regulation in females (medium).

\subsection{Hypothesis Testing}

Hypothesis (H1). With regard to test of knowledge, an interaction effect (Time $\mathrm{x}$ Treatment) was found for VKT. The FLIP group increased significantly more in this variable after the intervention compared to the control group, in both males $(\mathrm{F}(1)=17.636, p=$ $\left.<.001 ; \eta_{\mathrm{p}}^{2}=0.125\right)$, and females $\left(\mathrm{F}(1)=25.562, p=<.001 ; \eta_{\mathrm{p}}^{2}=\right.$ .159). Therefore, $\mathrm{H} 1$ was supported.

Hypothesis (H2). According to motivation, an interaction effect (Time $\mathrm{x}$ Treatment) was found for intrinsic motivation, but only in males $\left(\mathrm{F}(1)=16.287, p=<.001 ; \eta_{\mathrm{p}}^{2}=.116\right)$, i.e., males 
in the experimental group significantly improved their intrinsic motivation more than the control group. H2 was partially supported (only boys).

Hypothesis (H3). According to extrinsic motivation, an interaction effect (Time $\mathrm{x}$ Treatment) was found for identified regulation, but only in females $\left(\mathrm{F}(1)=5.700, p=0.018 ; \eta_{\mathrm{p}}^{2}=\right.$ 0.041), where a more significant decrease among the experimental group students was observed. On the other hand, an interaction effect (Time $\mathrm{x}$ Treatment) was found for introjected regulation, but only in females $(\mathrm{F}(1)=7.889, p=$ $\left..006 ; \eta_{p}^{2}=0.055\right)$. That is, the FLIP group increased significantly more in this variable after the intervention compared to the control group. Therefore, H3 was supported.

Hypothesis (H4). According to amotivation, no interaction effect (Time $\mathrm{x}$ Treatment) was found. H4 was not supported.

\section{DISCUSSION}

The aim of this study was to evaluate the effects of the use of a FL approach in secondary PE students regarding learning of the conceptual content of the activity itself, in this case volleyball. Additionally, the study aimed to evaluate how the FL approach affected their motivation in a SDT perspective. The main finding was that applying a FL approach had a positive effect on both student motivation and learning in secondary PE, but there seem to be differences between the sexes.

Regarding the learning, an interaction effect was found for the volleyball knowledge test (VKT). The FLIP group increased significantly more in this variable after the intervention compared to the control group, and this was observed across sex. This result is in line with similar findings among secondary school PE students in Norway benefiting in their learning of health-related fitness knowledge (HRFK) when experiencing a FL approach (Østerlie and Mehus, 2020). FL seems to improve cognitive learning in PE by supporting explanatory reasoning and in acting as an autonomous, encouraging environment, fostering the students' incorporation process (Yough et al., 2017). Further, it seems that FL promotes a perception of PE as being more meaningful, as Østerlie and Mehus (2020) argued that students found cognitive learning about the activity interesting. Students seem not to want to attend or focus on cognitive learning in PE arenas (Østerlie and Kjelaas, 2019; Østerlie and Mehus, 2020). As the FL approach alters somewhat where the focus on cognitive learning lies, moving it outside of the gymnastics hall or wherever PE takes place, seems to result in an enhanced desire for cognitive learning. Students' development of health-related fitness knowledge and $\mathrm{PA}$ behavior in PE are in several studies argued to correlate in a positive way (Chen et al., 2013; Thompson and Hannon, 2012), and also some scholars believe that more research is needed to explain the impact of students' health-related fitness knowledge on reflection, understanding, physical activity behavior, and overall physical literacy levels (Demetriou et al., 2015). Nevertheless, this study found a significant increase in learning acquisition, in the form of a VKT, among students who attended the FL class when compared to the control students. In other words, FL seems to enhance students' cognitive learning opportunities in upper secondary $\mathrm{PE}$.

Differing from the findings in the present study, an earlier inquiry on motivation in $\mathrm{PE}$ reveals that boys have higher autonomous motivation than girls (Säfvenbom et al., 2014; Wang et al., 2016; Østerlie and Mehus, 2020). In the present study, it was observed that girls and boys benefited differently from the FL approach when compared to the control group. The boys' intrinsic motivation significantly increased, while the girls' identified regulation was observed to decrease. Both types of motivation are considered to belong to the autonomous side of the motivational continuum seen through the SDT lens (Ryan and Deci, 2017). Regarding controlled motivation, we found girls and boys to be affected differently. The somewhat external motivation variable introjected regulation, and the variable external regulation were only significantly different in girls when compared to the control group.

An important goal of $\mathrm{PE}$, and in schooling in general, is to nurture the inherent interest that exists within the student. As this study reveals a possible difference in how girls and boys benefit from a FL approach in $\mathrm{PE}$, it is important that $\mathrm{PE}$ teachers consciously use this approach for all students to learn and develop in accordance with the aims and desired outcomes in PE. SDT implies three basic psychological needs (autonomy, competence, and relatedness), the nutrients required by a student to actively and confidently engage in learning. These needs are inherent, and their satisfaction is essential to promote intrinsic motivation and internalized forms of extrinsic motivation (i.e., the process by which non-fun activities can still be valued and embraced by learners) (Ryan and Deci, 2017). Our findings find support in other studies also discovering that boys and girls seem to somewhat differ in how (or if) they benefit from a FL approach in PE in terms of autonomous motivation (Østerlie and Mehus, 2020).

In total, the FL group had better development of their autonomous motivational variables after the intervention compared to the control group. This finds support in other work looking into how FL influences student motivation in PE seen from a SDT perspective (Østerlie and Mehus, 2020). Among Spanish primary and secondary PE students, Hinojo et al. (2020) found FL to enhance the sense of autonomy, resulting in the conclusion that $\mathrm{FL}$ is an effective teaching and learning approach in PE. On the other hand, and somewhat opposing the findings in the present study, scholars like Chiang et al. (2018) found girls to take better advantage of the FL approach, as they were more likely to use the opportunity to see instructional videos, online, outside school hours. Finally, one must interpret the findings in the present study with findings that both diverge and converge in their conclusions, such as the results from Ferriz-Valero et al. (2017), CamposGutiérrez et al. (2021), and Gómez-García et al. (2019), who found FL not to affect student motivation and/or learning in PE. This variety in findings might be caused by the reality that FL in PE is still in its very infancy, both in practice and in 
research, and that most studies still evolve around fragmented parts of the subject PE, and for shorter time of periods. The definition of what learning is in $\mathrm{PE}$, and how learning is understood, operationalized, and measured, might also cause divergent findings across studies.

\section{LIMITATIONS AND FUTURE LINES OF RESEARCH}

There are both strengths and limitations in this study. One asset is the use of a highly established theoretical lens to examine student motivation in the PE context. A limitation might be the possibility of generalization as all participants were from the same school. One limitation of this study is its lack of qualitative data, which could shed more light on students' experiences, especially, between boys and girls. Although this study sample (both girls and boys) may suffice given the research design, future research could perhaps extend the sample. Another limitation of this study is using a single learning content, in this case, volleyball. Future research is needed (quantitative and, especially, qualitative, or mixed) to deepen awareness of the causes that origin a motivational difference in FL application in boys and girls and, probably, if it is related to the satisfaction of some basic psychological need. Although the duration of this intervention is considered to be in line with the duration of the common teaching units in the present educational system, longitudinal studies are necessary to know the long-term psychological effects preferably across cultures and nations. Finally, one limitation of this study and common to all quasi-experimental interventions is that some people to work harder and perform better when they are participants in an experiment (Hawthorne effect, (Payne and Payne, 2004)).

\section{CONCLUSION}

As digital technology seems to infuse all parts of society, it is vital to invent, create and improve pedagogical approaches in all school subjects to benefit from these technologies. The pedagogical approach named flipped learning (FL) has gained recognition in physical education (PE) in recent years. However, there is limited inquiry looking into how this approach impacts students in their learning in PE, and their motivation towards PE. This study suggests that Spanish upper secondary students

\section{REFERENCES}

Akçayır, G., and Akçayır, M. (2018). The Flipped Classroom: A Review of its Advantages and Challenges. Comput. Edu. 126, 334-345. doi:10.1016/j. compedu.2018.07.021

Bergmann, J., and Sams, A. (2012). Flip Your Classroom: Reach Every Student in Every Class Every Day. Eugene: ISTE. Available from: http://site.ebrary.com/lib/ ntnu/detail.action?docID=10759765.

Birgili, B., Seggie, F. N., and Oğuz, E. (2021). The Trends and Outcomes of Flipped Learning Research between 2012 and 2018: A Descriptive Content Analysis. J. Comput. Educ. 8 (3), 365-394. doi:10.1007/s40692-021-00183-y benefited from a FL approach in their cognitive learning about volleyball in PE when compared to the control group. Regarding motivation, a FL approach seems to be beneficial when compared to the control group, but there were some differences according to sex, where boys seemed to better develop autonomous motivation more than girls. The findings in the present study could be useful for policymakers and stakeholders looking to promote the integration of digital technology into $\mathrm{PE}$ as part of improving the outcomes of PE for all students.

\section{DATA AVAILABILITY STATEMENT}

The raw data supporting the conclusion of this article will be made available by the authors, without undue reservation.

\section{ETHICS STATEMENT}

The studies involving human participants were reviewed and approved by the study was approved by the University of AlicanteÂ's Research Ethics Committee on 2 September 2020, and given the code UA-2020-09-02. Written informed consent from the participants' legal guardian/next of kin was not required to participate in this study in accordance with the national legislation and the institutional requirements.

\section{AUTHOR CONTRIBUTIONS}

$\mathrm{AF}-\mathrm{V}, \mathrm{O} \varnothing$, and SB-M contributed to the conception and design of the study. AF-V, AP-T, and O $\varnothing$ collected the data. AF-V managed the data, performed the statistical analysis, and created the figures and tables. AF-V and $O \varnothing$ wrote the first draft of the manuscript. All authors contributed to manuscript revision, and read and approved the submitted version.

\section{FUNDING}

This research was supported by Consejo Superior de Deportes (Spain) under Grant 20/UPB/21-Research Network for the Promotion of Equality and Physical Activity in Education.

Botella, Á. G., García-Martínez, S., García, N. M., Olaya-Cuartero, J., and Ferriz Valero, A. (2021). Flipped Learning to Improve Students' Motivation in Physical Education. Acta Gymnica 51 (e2021.012), 1-8. doi:10.5507/ag. 2021.012

Brewer, R., and Movahedazarhouligh, S. (2018). Successful Stories and Conflicts: A Literature Review on the Effectiveness of Flipped Learning in Higher Education. J. Comput. Assist. Learn. 34 (4), 409-416. doi:10. $1111 /$ jcal.12250

Campos-Gutiérrez, L. M., Sellés-Pérez, S., García-Jaén, M., and Ferriz-Valero, A. (2021). Aula Invertida En Educación Física: Aprendizaje, Motivación Y Tiempo De Práctica Motriz. Rimcafd 21 (81), 63-81. doi:10.15366/ rimcafd2021.81.005 
Castro-Sánchez, M., Linares-Manrique, M., Sanromán-Mata, S., and Pérez Cortés, A. J. (2017). Análisis de los comportamientos sedentarios, práctica de actividad física y uso de videojuegos en adolescentes. Sportis Sci. J. 3 (2), 241-255. doi:10. 17979/sportis.2017.3.2.1746

Chen, L.-L. (2016). Impacts of Flipped Classroom in High School Health Education. J. Educ. Tech. Syst. 44 (4), 411-420. doi:10.1177/0047239515626371

Chen, S., Chen, A., Sun, H., and Zhu, X. (2013). Physical Activity and Fitness Knowledge Learning in Physical Education: Seeking a Common Ground. Eur. Phys. Edu. Rev. 19 (2), 256-270. doi:10.1177/1356336X13486058

Cheng, L., Ritzhaupt, A. D., and Antonenko, P. (2018). Effects of the Flipped Classroom Instructional Strategy on Students' Learning Outcomes: a MetaAnalysis. Education Tech Res. Dev 67 (4), 793-824. doi:10.1007/s11423-0189633-7

Cheng, S.-C., Hwang, G.-J., and Lai, C.-L. (2020). Critical Research Advancements of Flipped Learning: A Review of the Top 100 Highly Cited Papers. Interact. Learn. Environ., 1-17. doi:10.1080/10494820.2020.1765395

Chiang, T. H.-C., Yang, S. J. H., and Yin, C. (2018). Effect of Gender Differences on 3-on-3 Basketball Games Taught in a mobile Flipped Classroom. Interactive Learn. Environments 27 (8), 1093-1105. doi:10.1080/10494820.2018.1495652

Cohen, J. (1988). Statistical Power Analysis for the Behavioral Sciences. 2nd ed. Laurence Erlbaum.

Coolican, H. (2018). Research Methods and Statistics in Psychology. 7 ed. London: Routledge.

Cuenca-Ruano, P., Martínez, S. G., Ferriz-Valero, A., and Martínez, J. T. (2021). Análisis comparativo de los perfiles motivacionales y el Estado de Flow entre una metodología tradicional y la metodología Flipped Classroom en estudiantes de Educación Física. Retos: nuevas tendencias en educación física, deporte y recreación 39, 338-344. doi:10.47197/retos.v0i39.78574

Demetriou, Y., Sudeck, G., Thiel, A., and Höner, O. (2015). The Effects of SchoolBased Physical Activity Interventions on Students' Health-Related Fitness Knowledge: A Systematic Review. Educ. Res. Rev. 16, 19-40. doi:10.1016/j. edurev.2015.07.002

Dominguez-Lara, S. (2018). Magnitud del efecto, una guía rápida. Educación Médica 19 (4), 251-254. doi:10.1016/j.edumed.2017.07.002

Faul, F., Erdfelder, E., Lang, A. G., and Buchner, A. (2007). G*Power 3: a Flexible Statistical Power Analysis Program for the Social, Behavioral, and Biomedical Sciences. Behav. Res. Methods 39 (2), 175-191. doi:10. 3758/bf03193146

Felgueras Custodio, N., and Delgado Pintor, M. (2021). Experiencia didáctica empírica sobre la clase invertida en el área de Educación Física (Empirical didactic experience about flipped classroom on Physical Education area). Retos 42, 189-197. doi:10.47197/retos.v42i0.83002

Fernandez-Rio, J., de las Heras, E., González, T., Trillo, V., and Palomares, J. (2020). Gamification and Physical Education. Viability and Preliminary Views from Students and Teachers. Phys. Edu. Sport Pedagogy 25, 509-524. doi:10. 1080/17408989.2020.1743253

Ferriz-Valero, A., Sebastià, S. A., and García, S. M. (2017). "Clase invertida como elemento innovador en educación física: Efectos sobre la motivación y la adquisición de aprendizajes en primaria y bachillerato," in Investigación en docencia universitaria. Diseñando el futuro a partir de la innovación educativa. Editor R. Roig-Vila, 211-222. Octaedro Editorial https://rua.ua.es/dspace/bitstream/10045/71112/1/Investigacion-en-docenciauniversitaria_23.pdf.

Galindo-Domínguez, H., and Bezanilla, M.-J. (2019). A Systematic Review of Flipped Classroom Methodology at university Level in Spain. Int. J. Tech. Educ. Innovation 5 (1), 81-90. doi:10.24310/innoeduca.2019.v5i1.4470

García, I. G., Lemus, N. C., and Morales, P. T. (2015). The Flipped Classroom through the Smartphone: Effects of its Experimentation in High School Physical Education. Prisma Soc. 15, 296-351.

Gimeno, B. P., Salguero, F. L., and Ariño, A. P. (2015). Relación entre las tecnologías de la información y la comunicación con el rendimiento académico y la práctica de la actividad física en educación primaria. Didáctica, Innovación y Multimedia (DIM) 11 (32), 1-10.

Gómez-García, G., Marín-Marín, J. A., Romero-Rodríguez, J.-M., Ramos NavasParejo, M., and Rodríguez Jiménez, C. (2020). Effect of the Flipped Classroom and Gamification Methods in the Development of a Didactic Unit on Healthy Habits and Diet in Primary Education. Nutrients 12 (8), 2210-2215. doi:10. $3390 /$ nu12082210
Gómez-García, J., Sellés-Pérez, S., and Ferriz-Valero, A. (2019). Flipped Classroom como propuesta en la mejora del rendimiento académico y motivación del alumnado en Educación Física. Kronos 18 (2), 1-12. Available from: https://gse.com/flipped-classroom-como-propuesta-en-la-mejora-del-rendimientoacademico-y-motivacion-del-alumnado-en-educacion-fisica-2753-sai5e0a32d14a026.

Han, H., and Røkenes, F. M. (2020). Flipped Classroom in Teacher Education: A Scoping Review. Front. Educ. 5 (221), 1-20. doi:10.3389/feduc.2020.601593

Hinojo Lucena, F. J., López Belmonte, J., Fuentes Cabrera, A., Trujillo Torres, J. M., and Pozo Sánchez, S. (2020). Academic Effects of the Use of Flipped Learning in Physical Education. Int. J. Environ. Res. Public Health 17 (1), 276. doi:10.3390/ ijerph17010276

Jong, M. S.-Y. (2017). Empowering Students in the Process of Social Inquiry Learning through Flipping the Classroom. J. Educ. Tech. Soc. 20 (1), 306-322.

Karabulut-Ilgu, A., Jaramillo Cherrez, N., and Jahren, C. T. (2018). A Systematic Review of Research on the Flipped Learning Method in Engineering Education. Br. J. Educ. Technol. 49 (3), 398-411. doi:10. $1111 /$ bjet. 12548

Koh, K. T., Li, C., and Mukherjee, S. (2021). Preservice Physical Education Teachers' Perceptions of a Flipped Basketball Course: Benefits, Challenges, and Recommendations. J. Teach. Phys. Edu. 40, 589-597. doi:10.1123/jtpe. 2019-0195

Låg, T., and Sæle, R. G. (2019). Does the Flipped Classroom Improve Student Learning and Satisfaction? A Systematic Review and Meta-Analysis. AERA Open 5 (3), 233285841987048-17. doi:10.1177/2332858419870489

Li, R., Lund, A., and Nordsteien, A. (2021). The Link between Flipped and Active Learning: A Scoping Review. Teach. Higher Edu., 1-35. doi:10.1080/13562517. 2021.1943655

Marqués, L., Palau, R., Usart, M., and Morilla, F. (2019). The Flipped Classroom in the Learning of Korfball in Fifth and Sixth Grade. Aloma 37 (2), 43-52. doi:10. 51698/aloma.2019.37.210.51698/aloma.2019.37.2.43-52

Moreno-Guerrero, A.-J., Soler-Costa, R., Marín-Marín, J.-A., and López-Belmonte, J. (2021). Flipped Learning and Good Teaching Practices in Secondary Education. Comunicar: Media Edu. Res. J. 29 (68), 107-117. doi:10.3916/ c68-2021-09

Ntoumanis, N. (2001). A Self-Determination Approach to the Understanding of Motivation in Physical Education. Br. J Educ Psychol 71 (2), 225-42. doi:10. $1348 / 000709901158497$

Ojalvo, H., and Doyne, S. (2011). Five Ways to Flip Your Classroom with the New York Times. New York Times. Available from: https://learning.blogs. nytimes.com/2011/12/08/five-ways-to-flip-your-classroom-with-the-newyork-times/.

Østerlie, O., and Kjelaas, I. (2019). The Perception of Adolescents' Encounter with a Flipped Learning Intervention in Norwegian Physical Education. Front. Educ. 4 (114), 1-12. doi:10.3389/feduc.2019.00114

Østerlie, O., and Mehus, I. (2020). The Impact of Flipped Learning on Cognitive Knowledge Learning and Intrinsic Motivation in Norwegian Secondary Physical Education. Edu. Sci. 10 (110), 110-16. doi:10.3390/ educsci10040110

Payne, G., and Payne, J. (2004). “The Hawthorne Effect," in Key Concepts in Social Research. Editors G. Payne and J. Payne (London: SAGE), 108-111.

Quintas, A., Bustamante, J.-C., Pradas, F., and Castellar, C. (2020). Psychological Effects of Gamified Didactics with Exergames in Physical Education at Primary Schools: Results from a Natural experiment. Comput. Edu. 152 (103874), 103874-17. doi:10.1016/j.compedu.2020. 103874

Ryan, R. M., and Deci, E. L. (2017). Self-determination Theory: Basic Psychological Needs in Motivation, Development, and Wellness. New York, NY: The Guilford Press.

Säfvenbom, R., Haugen, T., and Bulie, M. (2014). Attitudes toward and Motivation for PE. Who Collects the Benefits of the Subject? Phys. Edu. Sport Pedagogy 20 (6), 629-646. doi:10.1080/17408989.2014. 892063

Sánchez-Oliva, D., Marcos, F. M. L., Amado, D., Alonso, I. G.-P., and García-Calvo, T. (2012). Desarrollo de un cuestionario para valorar la motivación en educación física. Revista Iberoamericana de Psicología Del. Ejercicio y El Deporte 7 (2), 227-250. 
Thompson, A., and Hannon, J. C. (2012). Health-related Fitness Knowledge and Physical Activity of High School Students. The Phys. Educator 69 (1), 71-88.

Van Der Horst, K., Paw, M. J., Twisk, J. W., and Van Mechelen, W. (2007). A Brief Review on Correlates of Physical Activity and Sedentariness in Youth. Med. Sci. Sports Exerc. 39 (8), 1241-50. doi:10.1249/mss. ob013e318059bf35

Vansteenkiste, M., Niemiec, C. P., and Soenens, B. (2010). The Development of the Five Mini-Theories of Self-Determination Theory: An Historical Overview, Emerging Trends, and Future Directions. In The Decade Ahead: Theoretical Perspectives on Motivation and Achievement (Vol. 16 Part A, pp. 105-165). Emerald Group Publishing Limited. doi:10.1108/S0749-7423(2010) 000016A007

Verjans-Janssen, S. R. B., Van Kann, D. H. H., Gerards, S. M. P. L., Vos, S. B., Jansen, M. W. J., and Kremers, S. P. J. (2018). Study Protocol of the Quasi-Experimental Evaluation of "KEIGAAF": a Context-Based Physical Activity and Nutrition Intervention for Primary School Children. BMC Public Health 18 (842), 842-12. doi:10.1186/s12889018-5764-3

Wang, J. C., Morin, A. J., Ryan, R. M., and Liu, W. C. (2016). Students' Motivational Profiles in the Physical Education Context. J. Sport Exerc. Psychol. 38, 612-630. doi:10.1123/jsep.2016-0153

Yough, M., Merzdorf, H. E., Fedesco, H. N., and Cho, H. J. (2017). Flipping the Classroom in Teacher Education: Implications for Motivation and Learning. J. Teach. Edu. 70 (5), 410-422. doi:10.1177/ 0022487117742885

Zou, D., Luo, S., Xie, H., and Hwang, G.-J. (2020). A Systematic Review of Research on Flipped Language Classrooms: Theoretical Foundations, Learning Activities, Tools, Research Topics and Findings. Comp. Assist. Lang. Learn., 1-27. doi:10. 1080/09588221.2020.1839502

Conflict of Interest: The authors declare that the research was conducted in the absence of any commercial or financial relationships that could be construed as a potential conflict of interest.

Publisher's Note: All claims expressed in this article are solely those of the authors and do not necessarily represent those of their affiliated organizations, or those of the publisher, the editors, and the reviewers. Any product that may be evaluated in this article, or claim that may be made by its manufacturer, is not guaranteed or endorsed by the publisher.

Copyright (C) 2022 Ferriz-Valero, Østerlie, Penichet-Tomas and Baena-Morales. This is an open-access article distributed under the terms of the Creative Commons Attribution License (CC BY). The use, distribution or reproduction in other forums is permitted, provided the original author(s) and the copyright owner(s) are credited and that the original publication in this journal is cited, in accordance with accepted academic practice. No use, distribution or reproduction is permitted which does not comply with these terms. 